\title{
Study of serum vitamin D level Among school children in Urban And Rural Areas of Manipur
}

\author{
Gaipu Longmei ${ }^{1}, \mathrm{KSH}$. Gomti Devi ${ }^{2}$, N.Victoria Devi ${ }^{3}$, L. Amarnath Sharma ${ }^{4}$, \\ IohborlangRymbai ${ }^{5}$, Rumi Deb Barma $^{6}$ \\ 1,2,3,4,5,6 Department of Physiology, Regional Institute of Medical Sciences, Imphal, Manipur, India.
}

\begin{abstract}
:
Background: Vitamin D plays an important role in bone and muscle growth and function specially during rapid growth periods in infancy and adolescent. Vitamin D deficiency is highly prevalent among children and adolescents worldwide.

Objectives: To study serum vitamin D level among school children in urban and rural areas of Manipur and to determine the correlation between vitamin $D$ and selected variables of interest like sex, habitation with reference to diet and social habits.

Material and methods: A Cross sectional study was conducted in the department of Physiology, RIMS and from selected schools of urban and rural districts of Manipur. Serum vitamin D was analyzed by using Automated Microplate ELISA Reader and analyzed by using SPSS version 21(IBM).

Result: Out of 205 students, status of vitamin D revealed normal 53(67.9\%) males \& 43(33.9\%) female, insufficiency 9(11.5\%) males \& 38(22.8\%) females and deficiency 16(20.5\%) males \& 55(43.3\%) females. Differences in the levels of vitamin D between males and females and between urban and rural are found to be statistically significant.

Conclusion: In this study 46.8\% student were having normal 25-OH(D) level. There is significant difference in 25-OH(D) level between gender, and between urban and rural areas in the study.

Keywords: Vitamin D, School children, Hypovitaminosis D.
\end{abstract}

\section{Introduction}

Vitamin D refers to a group of fat-soluble vitamin responsible for enhancing intestinal absorption of calcium, iron, magnesium, phosphate and zinc ${ }^{1}$ and also vitamin D is a classical steroid hormone, as its synthesis and activity occur in different locations, having both dietary and endogenous precursors. Vitamin D was first discovered by McCollum and Davis in 1913 and in 1932 Askew et al. isolated vitamin $\mathrm{D}_{2}$ from an irradiation mixture of ergosterol and later vitamin $\mathrm{D}_{3}$ was identified by Windaus and Bock in 1937, which was formed in the skin as a result of UV irradiation of 7-dehydrocholesterol and later on in 1978, actual isolation and identification of vitamin $\mathrm{D}_{3}$ was proved by Esvelt et al. by mass spectrometry. ${ }^{3}$

Very few foods naturally contain vitamin D, and foods that are fortified with vitamin D are often inadequate to satisfy either a child's or an adult's vitamin D requirement. Sources of vitamin D is mainly from synthesis of vitamin $\mathrm{D}$ (specifically cholecalciferol or vitamin $\mathrm{D}_{3}$ ) in the skin. Dermal synthesis of vitamin $\mathrm{D}$ from 7 dehydrocholesterol is dependent on sun exposure (specifically ultra violet B radiation). Other sources for vitamin $\mathrm{D}$ like vitamin $\mathrm{D}_{2}$ are from fungi like mushroom, fish liver oil. Vitamin $\mathrm{D}$ from diet or dermal synthesis from sunlight is biologically inactive. ${ }^{4}$ A circulating level of 25 -hydroxyvitamin D of $>75 \mathrm{nmol} / \mathrm{L}$, or $30 \mathrm{ng} / \mathrm{ml}$, is required to maximize vitamin D's beneficial effects for health. In the absence of adequate sun exposure, at least $800-1000$ IU vitamin $\mathrm{D}_{3} /$ day may be needed to achieve this in children and adults. ${ }^{5}$

Several forms of vitamin $\mathrm{D}$ exist. The two major forms are vitamin $\mathrm{D}_{2}$ or ergocalciferol, and vitamin $\mathrm{D}_{3}$ or cholecalciferol. Vitamin $\mathrm{D}$ without a subscript refers to either $\mathrm{D}_{2}$ or $\mathrm{D}_{3}$ or both. These are known collectively as calciferol. Chemically, the various forms of vitamin D are secosteroids, i.e., steroids in which one of the bonds in the steroid rings is broken. The structural difference between vitamin $\mathrm{D}_{2}$ and vitamin $\mathrm{D}_{3}$ is the side chain of $\mathrm{D}_{2}$ contains a double bond between carbons 22 and 23, and a methyl group on carbon $24{ }^{6}$

Vitamin $\mathrm{D}_{3}$ (cholecalciferol) after ingestion or from skin, is hydroxylated in the liver where it is converted into the prohormonecalcidiol (25-hydroxycholecalciferol or $25(\mathrm{OH}) \mathrm{D}$. Circulating calcidiol is then converted into calcitriol $\left[1,25\right.$ dihydrocholecalciferol or $\left.1,25(\mathrm{OH})_{2} \mathrm{D}\right]$ in the proximal tubules of the kidneys, the biologically active form of vitamin D. Following the final converting step in the kidney, calcitriol is released into the circulation. The active vitamin $\mathrm{D}$ metabolite calcitriol mediates its biological effects by binding to the vitamin D receptor(VDR). ${ }^{7}$ VDR(Vitamin D receptor) activation in the intestine, bone, kidney and parathyroid gland cells lead to the maintenance of calcium and phosphorus levels in the blood and to the maintenance of bone content. The conversion of calcidiol to calcitriol is catalyzed by the enzyme 25 -hydroxyvitamin $\mathrm{D}_{3} 1$ - 
alpha-hydroxylase, the levels of which are increased by parathyroid hormone (and additionally by low calcium or phosphate). ${ }^{8}$

Vitamin D deficiency is now recognized as a pandemic. It affects mainly the children and elderly population. The major cause of vitamin $\mathrm{D}$ deficiency is the lack of appreciation that sun exposure in moderation is the major source of vitamin D for most humans. Vitamin D deficiency is also common in those who are infirm and not exposed to sunlight like staying indoor or who live at latitude that do not provide them with sunlight mediated cholecalciferol during the winter month. ${ }^{9}$ Also dark skin have a higher risk of lower serum 25 hydroxyvitamin $\mathrm{D}[25(\mathrm{OH}) \mathrm{D}]$ concentrationas they contain more melanin to interfere in the synthesis of vitamin D. ${ }^{10}$

A diet deficient in vitamin $\mathrm{D}$ in conjunction with inadequate sun exposure causesrickets in children and osteomalacia in adult. In this condition there will be softening of bones, weak and deformed long bones and fracture due to impaired bone mineralization and bone damage because of vitamin D deficiency. ${ }^{11}$ Serum $25-$ $\mathrm{OH}$ vitamin $\mathrm{D}$ is not only a predictor for bone health but also an independent predictor for other diseases like cancer, cardiovascular diseases and other chronic diseases.

\section{Rationale of study.}

Most studies on the prevalence of vitamin D deficiency in adolescent population have been done in all over the world. There is a paucity of study on the subject in the north eastern part of India where the race, culture, socio-demographic pattern and dietary habits are different from the rest of the country. A study to determine the status of vitamin D among adolescent population of Manipur, a north eastern state in India, will be significant in terms of comparison with similar study population elsewhere and contribute to understanding the need for further studies and intervention in the region in the future.

\section{Materials And Method}

\section{Study Design:}

Cross sectional study

Setting:

Department of Physiology, RIMS, Imphal.

Selected government and private schools in Imphal(Urban area) and Thoubal district (rural area) of Manipur.

Study duration:

7(seven) months from February to August 2016

Study tool:

25-OH Vitamin D total ELISA (DIA source kit), Belgium.

Study population:

205 (two hundred and five) students from urban and rural areas of manipur were selected for the study.

Data collection:

$2 \mathrm{ml}$ of blood was collected from study participants, then centrifuged at $3500 \mathrm{rpm}$ for 10 minutes to collect the serum and tested for 25-OH Vitamin D level.

\section{Exclusion Criteria}

1. Subject having any current or previous chronic diseases.

2. Subject having any history of vitamin D deficiency.

3. History of thyroid, parathyroid, adrenal or gonadal disease.

4. History of any metabolic bone disease

5.Malignancy

6. Hepatic and Renal disease

7.Malabsorption syndrome or history of gastrointestinal resection, chronic diarrhea.

\section{Analysis:}

The subjects were divided into three groups according to their vitamin D status (deficiency $\leq 20 \mathrm{ng} / \mathrm{mL}$; insufficiency: $20-29 \mathrm{ng} / \mathrm{mL}$; sufficiency/normal $\geq 30 \mathrm{ng} / \mathrm{mL})^{12}$. Data was collected and analyzed statistically by using SPSS version 21(IBM). Descriptive statistics like mean, standard deviation and percentages were used. Chi square test is used to see the association between different variables. $\mathrm{P}<0.05$ is taken as statistically significant.

\section{Results}

Out of 205 students, $127(62 \%)$ were females and 78(38\%) were males. Status of vitamin D revealed normal 53(67.9\%) males \& 43(33.9\%) female, insufficiency $9(11.5 \%)$ males \& 38(22.8\%) females and 
deficiency $16(20.5 \%)$ males \& 55(43.3\%) females.Differences in the levels of vit.D between males and females and between urban and rural are found to be statistically significant.The study also showed some significant differences in sunlight exposure and skin colour though it was not statistically significant.

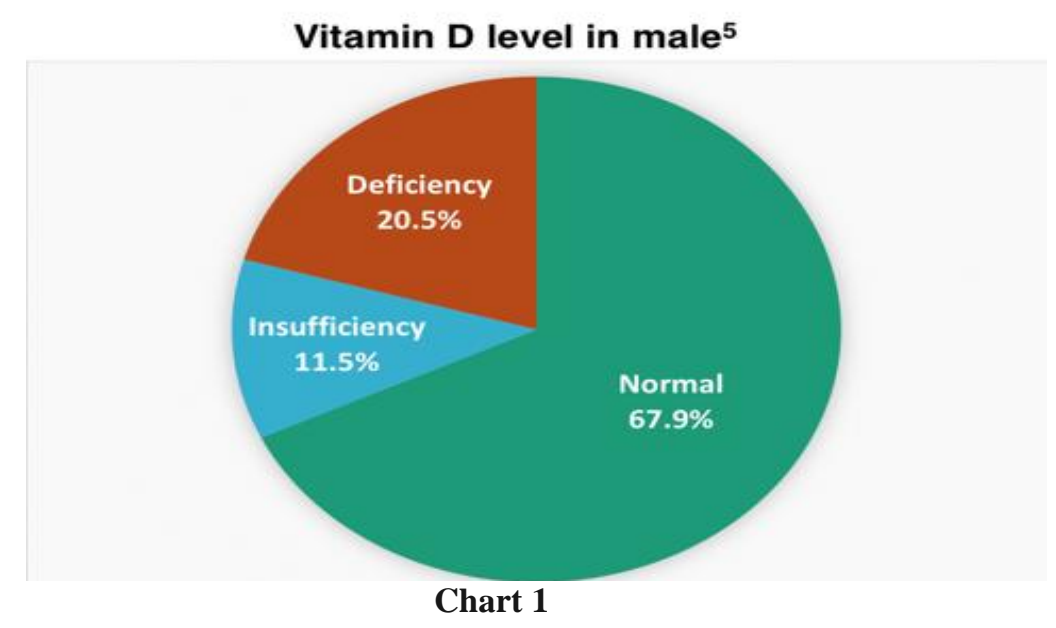

Chart 1:shows vitamin D level in male, out of 78 male students, $67.9 \%$ is normal, $11.5 \%$ insufficiency and $20.5 \%$ deficiency.

Vitamin D level in female

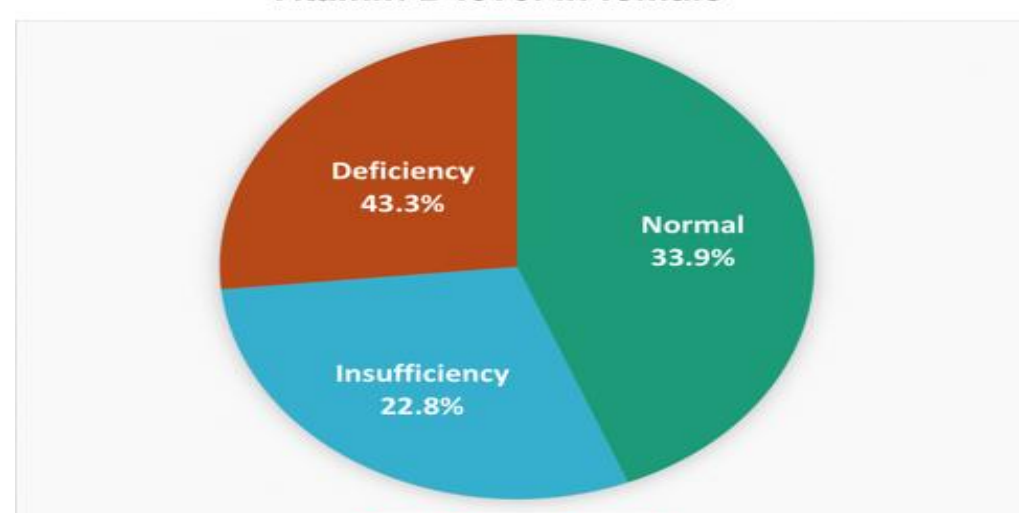

Chart 2

Chart 2: shows vitamin D level in female, out of 127 female students, $33.9 \%$ is normal, $22.8 \%$ insufficiency and $43.3 \%$ deficiency.

\section{Vit.D level in Urban area}

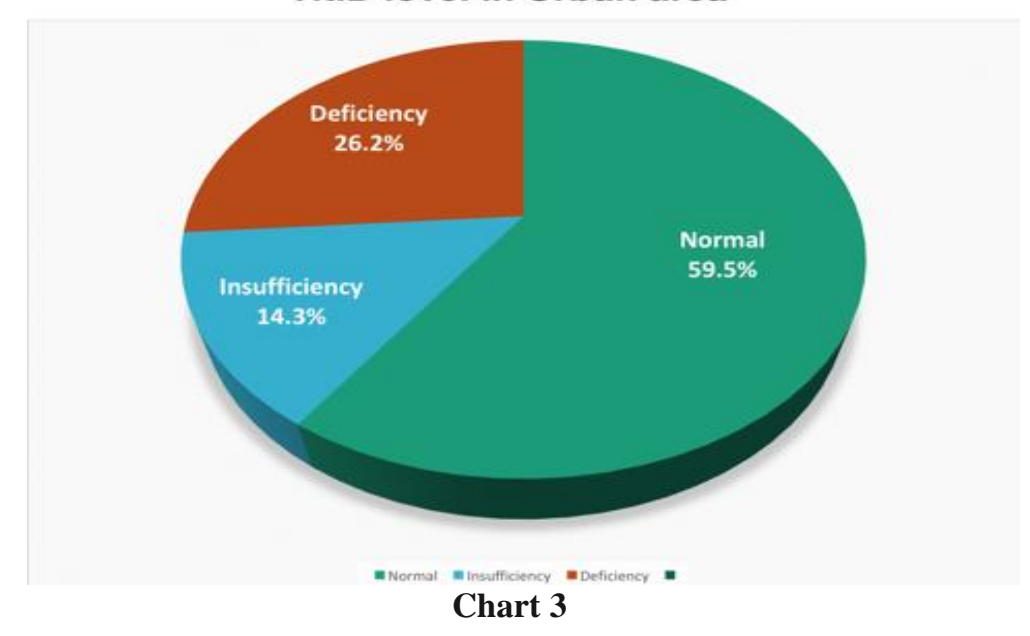


Chart 3:shows vitamin D level in urban area, 126 were from urban which shows 59.5\% normal, $14.3 \%$ insufficiency and $26.2 \%$ deficiency.

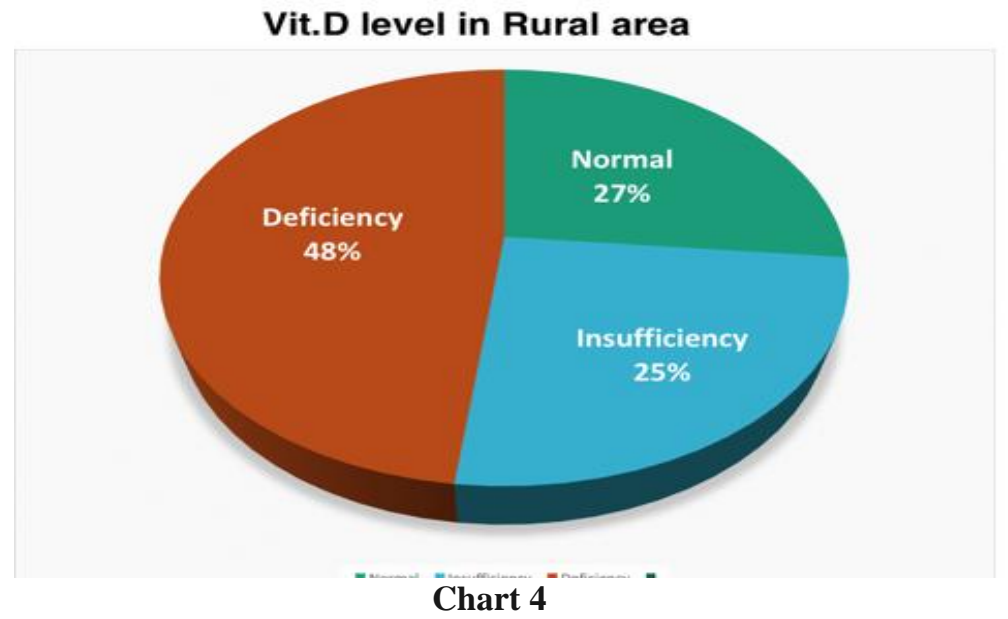

Chart 4: shows vitamin D level in rural area, 79 were from rural which shows $27 \%$ normal, $25 \%$ insufficiency and $48 \%$ deficiency.

Table 1: Correlation between sunlight exposure and vitamin D

\begin{tabular}{|c|c|c|c|c|c|}
\hline Sunlight exposure & \multicolumn{4}{|c|}{ Vitamin D level } & \multirow[b]{2}{*}{ P - Value } \\
\hline & Deficiency & Insufficiency & Normal & Total & \\
\hline$<1 \mathrm{hr} /$ day & $\begin{array}{l}38.0 \% \\
(30)\end{array}$ & $\begin{array}{l}16.5 \% \\
(13)\end{array}$ & $\begin{array}{l}45.6 \% \\
(36)\end{array}$ & $\begin{array}{r}100 \% \\
(79)\end{array}$ & \multirow{4}{*}{.425} \\
\hline 1-2hr/day & $\begin{array}{l}36.7 \% \\
(18)\end{array}$ & $\begin{array}{l}12.2 \% \\
(6)\end{array}$ & $\begin{array}{l}51.0 \% \\
(25) \\
\end{array}$ & $\begin{array}{r}100 \% \\
(49) \\
\end{array}$ & \\
\hline 2 or more $\mathrm{hr} / \mathrm{day}$ & $\begin{array}{l}29.9 \% \\
(23) \\
\end{array}$ & $\begin{array}{l}24.7 \% \\
(19)\end{array}$ & $\begin{array}{l}45.5 \% \\
(35) \\
\end{array}$ & $\begin{array}{r}100 \% \\
(77)\end{array}$ & \\
\hline Total & $\begin{array}{l}34.6 \% \\
(71)\end{array}$ & $\begin{array}{l}18.5 \% \\
(38)\end{array}$ & $\begin{array}{l}46.8 \% \\
(96)\end{array}$ & $\begin{array}{l}100 \% \\
(205)\end{array}$ & \\
\hline
\end{tabular}

Table 1: shows correlation between sunlight exposure and vitamin $\mathrm{D}$, it shows vitamin $\mathrm{D}$ deficiency and insufficiency are more in those who exposed to sunlight less than $1 \mathrm{hr} /$ day but not statistically significant.

Table 2: Correlation between skin colour and Vitamin D

\begin{tabular}{|l|l|l|l|l|l|}
\hline Skin colour & \multicolumn{2}{|l|}{ Vitamin D level } & P - Value \\
\hline & Deficiency & Insufficiency & Sufficiency & Total & \\
\hline Light brown & $47.6 \%$ & $14.3 \%$ & $38.1 \%$ & $100 \%$ & \\
& $(10)$ & $(3)$ & $(8)$ & $(21)$ & \multirow{2}{*}{.483} \\
\hline Dark brown & $32.6 \%$ & $19.3 \%$ & $48.1 \%$ & $100 \%$ & \\
& $(59)$ & $(35)$ & $(87)$ & $(181)$ & \\
\hline Very dark & $66.7 \%$ & $0.0 \%$ & $33.3 \%$ & $100 \%$ & \\
& $(2)$ & $(0)$ & $(1)$ & $(3)$ & \\
\hline Total & $34.6 \%$ & $18.5 \%$ & $46.8 \%$ & $100 \%$ & \\
& $(71)$ & $(38)$ & $(96)$ & $(205)$ & \\
\hline
\end{tabular}

Table 2: shows correlation between skin colour and vitamin D and it shows some vitamin D differences in different skin colour.

\section{Discussion}

Childhood and adolescence are critical periods in terms of skeletal development and bone density. In addition to genotype, physical activity, diet and sufficient vitamin D level are important factors for reaching optimal bone mass. The level of vitamin D is affected by many factors such as exposure to the sun, clothing style, skin pigmentation, latitude of region, consumption of dairy products and fish and vitamin supplementation. In the present study, out of 205 students, $46.3 \%$ students were having normal vitamin D level. In female, out of $127,43.3 \%$ were vitamin D deficiency, $22.8 \%$ were insufficiency and male, out of $78,20.5 \%$ were vitamin D deficient, $11.9 \%$ were insufficient and $67.9 \%$ were sufficient. From the above observation, it was found that female students were more in number of vitamin D deficiency as compare to male students, which is similar to other studies ${ }^{13}$. It may be due to less exposure of sunlight by female students as compare to male students and also due to dietary habits as female students usually take less non-vegetarian diet as compare 
to male students. This finding clearly indicates that vitamin D deficiency is an important health in school children specially in female which is similar to the study conducted by Kim MS et al ${ }^{14}$.

Out of 205 students, 126 students were from urban school and 79 students were from rural schools. In urban, vitamin D deficiency was $26.2 \%$, insufficiency was $14.3 \%$, sufficiency was $59.5 \%$. In rural schools, vitamin D deficiency was $48.1 \%$, insufficiency was $25.3 \%$, sufficiencywas $26.6 \%$.

From the above study, it was shown that vitamin D deficiency was more in rural area as compare to urban area. The differences may be due to dietary habits as urban students consumed more meat and fish as compare to rural area. Though rural students exposed more to sunlight, they usually exposed to sunlight in morning or evening as they were in school during the time where maximum vitamin D synthesis occur from skin usually between $11 \mathrm{am}$ to $2 \mathrm{pm}$. Out of 205 students, those who exposed less than $1 \mathrm{hr} /$ day, vitamin D deficiency was $38.0 \%$, insufficiency was $16.5 \%$ and sufficient was $45.6 \%$. Those who exposed between $1-2 \mathrm{hrs} / \mathrm{day}$, vitamin D deficiency was $36.7 \%$, insufficiency was $12.2 \%$, normal was $51.0 \%$.

Those who exposed 2 or more hrs/day, vitamin D deficiency was $29.9 \%$, insufficiency was $24.7 \%$, sufficiency was $46.8 \%$. From the above study, it was found that vitamin D deficiency was common among students who exposed less to sunlight which is similar to other study ${ }^{16}$ though it was not statistically significant.The study between skin colour and vitamin D showed that light brown skin had vitamin D deficiency of $47.6 \%$, insufficiency of $14.3 \%$ and sufficiency of $38.1 \%$, dark brown had vitamin D deficiency of $32.6 \%$, insufficiency of $19.3 \%$ and sufficiency of $48.1 \%$ and very dark had vitamin D deficiency of $66.7 \%$, insufficiency of $0 \%$ and sufficiency of $33.3 \%$.From the above, it was shown that vitamin D deficiency was common among darker skin which is similar to other study ${ }^{17}$. The darker skin is because of presence of more melanin which interfered in the formation of vitamin $\mathrm{D}_{3}$ in the skin from sunlight, which is the main source of vitamin D. In case of light brown skin, deficiency was more because these students exposed less to sunlight, though they had lighter skin. Among these students, females are more in number as compare to male, the reason was discussed earlier but the study was not statistically significant.

\section{Conclusion}

The current study found that vitamin D deficiency and insufficiency were common among study population. Deficiency was more in female, rural area and those who exposed less to sunlight. Health education mainly about sunlight ${ }^{18}$ and vitamin D supplementation are necessary to prevent vitamin D deficiency among the school students.

\section{References}

[1]. Holick MF. High prevalence of vitamin D inadequacy and implication for health. Mayo Clinic Proc J 2006 March; 81 (3): P $353-$ 373.

[2]. Best CH, Taylor NB. Vitamin D Structure and Biosynthesis. In: Tandon OP, Tripathi Y, editors. Best and Taylor's text book of Physiology. $13^{\text {th }}$ ed. Gurgaon: Wolters Kluwer (India); 2012 P 882.

[3]. DeLucaa HF. History of the discovery of vitamin D and its active metabolites. BoneKEy Rep 2014; 3: 479.

[4]. En.wikipedia. Vitamin D. 2015 June 13. Available from URL http://en.wikipedia.org/wiki/Vitamin D. Accessed June 162015.

[5]. Holick MF, Chen TC. Vitamin D deficiency: a worldwide problem with health consequences. Am Soc for ClinNutr $2008 ; 87$ (4): $1080 \mathrm{~S}-1086 \mathrm{~S}$.

[6]. Best CH, Taylor NB. Vitamin D Structure and Biosynthesis. In: Tandon OP, Tripathi Y, editors. Best and Taylor's text book of Physiology. 13 ${ }^{\text {th }}$ ed. Gurgaon: Wolters Kluwer (India); 2012 p 883.

[7]. Holick MF. Environmental factors that influence the cutaneous production of vitamin D. Am J ClinNutr1995;61 (3): 638S-645S

[8]. Best CH, Taylor NB. Vitamin D Structure and Biosynthesis. In: Tandon OP, Tripathi Y, editors. Best and Taylor's text book of Physiology. 13 $3^{\text {th }}$ ed. Gurgaon: Wolters Kluwer (India); 2012 p 884.

[9]. Holick MF. Environmental factors that influence the cutaneous production of vitamin D. Am J ClinNutr1995;61 (3): 638S-645S

[10]. En.wikipedia. Vitamin D. 2015 June 13. Available from URL http://en.wikipedia.org/wiki/Vitamin D. Accessed Jun 162015.

[11]. Grant WB, Holick MF. Benefits and requirements of vitamin D for optimal health. Altern Med Rev 2005 Jun; 10 (2): 94-111.

[12]. Vitamin D level chart by Endocrine society of US.

[13]. Andiran N, Celik N, Akca H, Dogan G. Vitamin D deficiency in children and adolescents J Clin Res PaedEndocrinol 2014; 4.

[14]. Kim MS, Kong YH, Lee DY. Hydroxy Vitamin D Status in Healthy Korean School Children and Adolescents. Striking Difference in Prevalence of Vitamin D Deficiency with School Grade and Season. HK J Paediatr (New Series) 2015; 20: 3-9.

[15]. Harinarayan CV, Holick MF, Prasad UV, Vani PS, Himabindu G. Vitamin D status and sun exposure in India. PMC Dermatoendocrinol J 2013 jan 1; 5(1): 130-141.

[16]. Maha MHKM, Khaled MA. Vitamin D deficiency in children living in Jeddah, Saudi Arabia. Indian J EndocrinolMetab 2012; 16 (2): 263-269.

[17]. Bonilla C, Ness AR, Wills AK, Lawlor DA, Lewis SJ, Smith GD. Skin pigmentation, sun exposure and vitamin D levels in children of the Avon longitudinal study of parents and children. BMC public Health 2014 Jun 12; 14:597.

[18]. Holick MF. Sunlight and vitamin D for bone health and prevention of autoimmune diseases, cancers, and cardiovascular disease. Am Soc for ClinNutr 2004 Dec; 80 (6): 1678S-1688S. 